\title{
Atomoxetine improves patient and family coping in attention deficit/hyperactivity disorder: a randomized, double-blind, placebo-controlled study in Swedish children and adolescents
}

\author{
Pär Svanborg • Gunilla Thernlund · \\ Per A. Gustafsson · Bruno Hägglöf · \\ Alexander Schacht · Björn Kadesjö
}

Received: 25 February 2008/ Accepted: 1 May 2009/Published online: 23 May 2009

(C) The Author(s) 2009. This article is published with open access at Springerlink.com

\begin{abstract}
This 10-week study assessed the efficacy of atomoxetine in combination with psychoeducation compared to placebo and psychoeducation in the improvement of Quality of Life in Swedish stimulant-naive children and adolescents with attention deficit/hyperactivity disorder. A total of 99 patients were treated with atomoxetine (49 patients) or placebo (50 patients) for 10 weeks and assessed regarding broader areas of functioning using the Quality of Life measures Child Health and Illness Profile-
\end{abstract}

P. Svanborg ( $₫)$
Eli Lilly Sweden AB, Box 721, 16927 Solna, Sweden
e-mail: svanborg_par@lilly.com
URL: http://www.clinicaltrials.gov
P. Svanborg
Department of Clinical Neuroscience, Psychiatry Section,
Karolinska Institutet, 17176 Stockholm, Sweden
G. Thernlund
Department of Child and Adolescent Psychiatry,
Clinical Sciences, Lund University, 22185 Lund, Sweden

P. A. Gustafsson

Child and Adolescent Psychiatry (BUP), University Hospital,

58185 Linköping, Sweden

B. Hägglöf

Division of Child and Adolescent Psychiatry, NUS,

Umeå University, Bu 23, 90187 Umeå, Sweden

A. Schacht

European Medical Information Science, Lilly Deutschland

GmbH, Saalburgstr. 153, 61350 Bad Homburg, Germany

B. Kadesjö

Department of Child and Adolescent Psychiatry, Drottning

Silvias Barnsjukhus, Barnneuropsykiatriska Kliniken (BNK),

University of Gothenburg, 41118 Göteborg, Sweden
Child Edition (CHIP-CE), Family Strain Index [FSI; equivalent to the Family Burden of Illness Module used in the study], Appraisal of Stress in Child-Rearing (ASCR), Five to fifteen (FTF), "I think I am" ("Jag tycker jag är"), and Children's Depression Rating Scale-Revised (CDRS-R) before and after the active treatment phase. Simultaneously, the patients' parents participated in a 4-session psychoeducation program. A statistically significant difference in favor of atomoxetine was seen in the improvement from baseline to study endpoint for the CHIP-CE domains "Achievement" and "Risk avoidance", for the FSI total score, for the ASCR section (I) domain "Child as a burden", for all FTF domains except for "Language and Speech", and for the CDRS-R total score. No difference between treatment groups was observed in the patient-assessed evaluation of self-esteem using the "I think I am" scale. Atomoxetine combined with psychoeducation had a positive effect on various everyday coping abilities of the patients as well as their families during 10 weeks of treatment, whereas the patients' selfimage and the parents' image of the climate in the family were not significantly improved.

Keywords ADHD - Atomoxetine - Quality of life · CHIP-CE · Broader efficacy
Abbreviations
ADHD Attention deficit/hyperactivity disorder
ADHD-RS Attention deficit/hyperactivity disorder rating scale
AE Adverse event
ANCOVA Analysis of covariance
ASCR Appraisal of Stress in Child-Rearing
CGI-I Clinical Global Impression-Improvement
CGI-S Clinical Global Impression-Severity
CDRS-R Children's Depression Rating Scale-Revised 


$\begin{array}{ll}\text { CHIP-CE } & \begin{array}{l}\text { Child Health and Illness Profile-Child } \\ \text { Edition }\end{array} \\ \text { FBIM } & \text { Family Burden of Illness Module } \\ \text { FSI } & \text { Family Strain Index } \\ \text { FTF } & \text { Five to fifteen } \\ \text { HRQL } & \text { Health-related quality of life } \\ \text { SCT } & \text { Standard current therapy }\end{array}$

\section{Introduction}

Attention deficit/hyperactivity disorder (ADHD) is a common disorder in children and adolescents, with a prevalence of $3-8 \%[2,34]$. The core symptoms of the disorder are ageinadequate difficulties in sustaining attention and/or hyperactivity/impulsivity, leading to functional impairments within at least two life domains, e.g., in school, at work, at home, etc. [2]. Current treatments of the disorder include pharmacotherapy, preferably in combination with behavioral and psychosocial interventions in order to enhance the patients' and parents' capability to cope with the symptoms and behavioral problems caused by ADHD, and to adapt the environment to the child's specific difficulties [5].

The efficacy of stimulants and atomoxetine, a nonstimulant first licensed in the US in 2002, has been well documented in clinical trials $[3,6]$. During the recent years, an increasing amount of research has investigated the health-related quality of life (HRQL) and the functional impairments of the daily life of patients with ADHD and their parents, rather than the core symptoms of the disorder, i.e., their "broader areas of functioning". However, such measures are still considered as not thoroughly investigated because of too infrequent applications or with too little statistical power [7, 9].

Previous research has indicated that ADHD is associated with a range of deficits in various areas of functioning such as low self-esteem, emotional liability, academic underachievement, disturbed peer relations, and family interaction $[4,22,26]$. The impairment of HRQL in children with ADHD has been compared with the impairment in children with somatic illness. For example, Escobar and coworkers [15] compared HRQL, as measured by the Child Health Questionnaire (CHQ-PF50) [20, 21], a generic, standardized measure covering four "physical" and seven "psychosocial" domains, in children with asthma, ADHD, and in healthy controls. The results show that children with ADHD were more severely impaired in their psychosocial and physical functioning than healthy children, but also that this impairment was even greater than in children with asthma, mainly in areas related to psychosocial functioning.

During the development of atomoxetine, the CHQ was used in several clinical trials in order to investigate the effect of the treatment on HRQL, beyond the effect on core ADHD symptoms. Perwien [29] summarized the results from three placebo-controlled atomoxetine studies with a duration of 78 weeks $[23,24,41]$ including 403 patients on atomoxetine and 181 on placebo. Atomoxetine-treated patients improved on all seven psychosocial outcomes (self-esteem, behavior, family activity, mental health, parent impact emotion, parent impact time, and role function), while no aggravations, or differences versus placebo were seen on the physical functioning domains. In an open-label long-term study, 912 patients started treatment on atomoxetine, and patients who continued the study were evaluated according to CHQ after an "acute" phase of 10 weeks, and at 6 and 24 months [30]. Similar improvements as reported above were seen already at 10 weeks in all psychosocial domains for those patients who completed the full trial. Taken together, these results suggest that improvements in HRQL as measured by the CHQ, which are associated with atomoxetine treatment, occur within a relatively short time frame.

Another generic measure of HRQL in children and adolescents is the Child Health and Illness Profile-Child Edition (CHIP-CE) [36, 37]. The CHIP-CE was used in a large European prospective observational study on children and adolescents with ADHD, the Attention Deficit/Hyperactivity Disorder Observational Research in Europe (ADORE) study [33], which assessed the primary objective to describe treatment regimens and HRQL during a 2-year period. The CHIP-CE consists of five domains and a total score, and similar to the CHQ, norms exist [37]. In the ADORE patient sample, the mean baseline scores of the Achievement and Risk avoidance domains were particularly deviant, indicating severe problems with school performance, peer relations, and risk taking behavior [36]. In the UK "Sunbeam" study [32] the CHIP-CE total score was used as the primary outcome measure in a randomized open-label 10-week comparison of the HRQL of approximately 200 children and adolescents treated with either atomoxetine or with "standard current therapy" (SCT). In the latter study arm, treatments were given at the physician's discretion, and more than $80 \%$ of patients in that arm received stimulants, with or without behavioral counseling. Similar to the ADORE, in Sunbeam the CHIP-CE Achievement and Risk avoidance domains were the most deviant domains at baseline. An improvement for both treatment arms was seen for all CHIPCE domains including the total score, with a statistically significantly greater improvement in atomoxetine-treated patients in the primary measure, the CHIP-CE total score, and in the five domain scores.

The present study was designed to investigate the changes in HRQL as measured by the CHIP-CE during treatment with atomoxetine and (parental) psychoeducation, compared to placebo and psychoeducation, in stimulant-naive children and adolescents with ADHD. The parental educational 
program itself, the efficacy of treatments on core ADHD symptoms, and safety outcomes are presented in detail in a separate paper [39]. As described above, in previous trials with CHIP-CE as a measure of HRQL in ADHD, the two domains of Achievement and Risk avoidance were most deviant at baseline and changed most after treatment. Therefore, the CHIP-CE Achievement domain was chosen as primary outcome measure for the present study. Treatment effects on health care resource utilization were also measured and results are reported elsewhere [25].

\section{Patients and methods}

Study design, study population, and study treatments of this multi-center, randomized, double-blind, placebo-controlled, phase 3b study (B4Z-SO-LY15) are described in detail elsewhere [39]. The study design and efficacy on core ADHD symptoms and safety results are briefly summarized below.

Patients were recruited consecutively from the clinics' waiting lists; no site advertised for participants. Patients had to be stimulant-naive and due to the relatively slow onset of action for atomoxetine, and the $50 \%$ chance of being randomized to placebo, not clinically assessed as being in need of immediate symptom relief. Important exclusion criteria included general impairment of intelligence, serious medical illness, a history of psychosis or bipolar disorder, alcohol or drug abuse within the previous 3 months, and ongoing use of psychoactive medication other than the study drug. Patients who required immediate pharmacotherapy or structured psychotherapy were also excluded. Of the 102 patients screened, 99 met the entry criteria and participated in the study.

After screening (Visit 1), eligible patients were randomized in a 1:1 ratio to a 10-week double-blind treatment with either atomoxetine $(n=49)$ or placebo $(n=50)$. Atomoxetine dosage was according to the EU label, i.e., $0.5 \mathrm{mg} /$ $\mathrm{kg}$ during the first week of treatment, thereafter $1.2 \mathrm{mg} / \mathrm{kg}$.

In parallel, the parents of the patients in both treatment groups participated in a 4-session psychoeducational training. The program was developed by a professional educational manager especially for the conditions associated with this clinical study. The content of the program contained core elements from more comprehensive behavioral treatment programs like parental management training (PMT), developed by Patterson and coworkers, e.g., [28] and the community parent education program (COPE), developed by Cunningham and coworkers, e.g., [10-12]. It consisted of four 3-h parental group sessions and was led by 1 or 2 group leaders at each site. Since the participating clinics had various experiences of psychoeducative methods, it was not considered feasible to include more than four 3-h "basic" sessions during the 10 weeks double-blind study period II. The group leaders were trained by the educational manager, and were provided with presentation slides and a written material aiming to increase the parents' knowledge of ADHD as a disorder, different kind of treatments, the disorder's psychological and behavioral consequences for the child and its family, and how to cope better with these consequences. Both parents/caregivers were invited and encouraged to participate, and did so in the majority of cases. Since the program was not monitored by the sponsor, it is not possible to present any absolute numbers of attendance. The psychoeducation is more thoroughly described in a previous paper [39].

Atomoxetine or placebo was dispensed at 6 visits (Visits 2-7) during the active treatment phase. After completion of the double-blind phase, all patients were offered the option of entering an open-label extension, during which all patients received atomoxetine until it became commercially available in Sweden, but for no longer than 9 months. This paper reports results from the double-blind phase of the study.

Written informed consent was obtained before any study-related procedures. The study was conducted according to good clinical practice guidelines.

Summary of demographics, baseline characteristics, efficacy and safety parameters

Demographics and baseline characteristics were similar in both treatment groups. The study population was predominantly male $(80.8 \%)$ and diagnosed with the combined ADHD subtype (77.8\%). Baseline total ADHD-RS scores expressed as mean (SD) were 38.9 (7.7) and 39.5 (6.7) for atomoxetine and placebo-treated patients, respectively. The ADHD diagnosis as well as comorbid conditions were confirmed with the Kiddie Schedule for Affective Disorders and Schizophrenia for School-Age Children-Present and Lifetime Version (K-SADS-PL) [19]. The most frequent comorbid disorder was oppositional/defiant disorder (20.2\%), followed by tics (14.1\%) and major depressive disorder (5.1\%: 2 patients on atomoxetine, 3 on placebo). No patient fulfilled criteria for conduct disorder. The least square mean (lsmean) change from baseline to endpoint in total ADHD-RS score was -19.0 for atomoxetine patients and -6.3 for placebo patients, resulting in an effect size of 1.3 at endpoint. Treatment response, as measured by a reduction in ADHD-RS score of $\geq 25 \%$ (or $\geq 40 \%$ ) was achieved in $71.4 \%$ (or $63.3 \%$, respectively), of atomoxetine patients and $28.6 \%$ (or $14.3 \%$ ) of placebo patients. The lsmean change from baseline to endpoint in CGI-Severity was -1.8 in the atomoxetine group compared with -0.3 in the placebo group. The difference between treatments in CGI-Improvement at endpoint was -1.4 points in favor of atomoxetine. No serious adverse events (SAEs) occurred. 
The safety profile was in line with the label, with headache, fatigue, and gastrointestinal symptoms (abdominal pain upper and anorexia/decreased appetite) most commonly reported. No patient discontinued during the double-blind study period II [39].

\section{Assessments}

The primary efficacy variable of this study was the domain "Achievement" of the Child Health and Illness Profile-Child Edition-Parent Form (CHIP-CE-Parent form) [37], a 76-item generic HRQL questionnaire covering a total of 5 domains ("Satisfaction", "Comfort", "Risk avoidance", "Resilience", and "Achievement"). The CHIP-CE scores are standardized to $t$ scores, i.e., to a mean $\pm \mathrm{SD}$ of $50 \pm 10$, based on the norms of a sample of 1,049 US school children, with higher scores indicating better health. Scores of the other CHIP-CE-Parent form domains, and the CHIP-CE total score (the mean of the separate domains) [35], were assessed as secondary efficacy measures. Based on a factor analysis from the ADORE study [33], Riley and her group [36] reported that the "Achievement" domain's subdomains "Peer relations" and "Academic performance" appeared as separate factors in an ADHD sample, so that the CHIP-CE now comprises six domains instead of the initial five. Thus, results from the aforementioned subdomains are also presented. An improvement is indicated by an increase in scores.

Further secondary outcomes were the mean changes in several other HRQL assessments: the Family Strain Index (FSI), a newly developed 6-item questionnaire to determine the effect of a child's ADHD on the functioning of their immediate family, was investigated for the 2 domains "Emotional" and "Restriction" in the 4 settings "Global", "Home", "Outside home", and "Family". A high FSI score indicates a high family strain. The FSI was recently validated by Riley and her group [38] based on data from the ADORE study [33], in which 1,477 parents of patients aged 6-18 years completed the form. A factor analysis of the data from this study [38] showed that the FSI taps into an overall experience of worry and interruptions of activities in families of children with ADHD, and a single factor (e.g., the total score) was identified with excellent internal consistency and almost no ceiling or floor effects were observed for this special population. The FSI was also used in the Sunbeam study [32]; however, the instrument was named the Family Burden of Illness Module (FBIM), likewise in the present study.

Appraisal of Stress in Child-Rearing (ASCR) was originally constructed and evaluated in Holland (Nijmegen ChildRearing Situation Questionnaire; NCSQ). The NCSQ considers measures on child-rearing in four different sections; in the present study only the first two were used: (1) subjective parenting stress; (2) global appraisal of the child-rearing situation. Section (1) consists of 46 items, covering 8 different concepts of stress, such as strain, burden, problems, etc. It was translated to Swedish and validated in a sample of parents to children with and without ADHD. The Swedish version has appropriate psychometric properties [18]. The NCSQ was used as a measure of changes in parents' attitudes towards their children during the study.

The "Five to fifteen" (FTF) questionnaire [17] was developed in Scandinavia and consists of 181 parent assessed items covering the 8 developmental/neuropsychiatric domains "Motor control", "Executive function", "Perception", "Memory", "Language and speech", "Learning", "Social competence", and "Emotional/behavioral problems". They indicate their agreement/disagreement on each item, containing a short, specific statement, e.g., "Interrupts or intrudes on others" or "Loses temper" with $0=$ "does not apply", 1 = "applies sometimes or to some extent", and $2=$ "definitely applies". Norms exist for Scandinavian children and adolescents between 5 and 15 years, and the FTF has also been validated in children with ADHD and other neuropsychiatric disorders [1].

The"I think I am" ("Jag tycker jag är") scale [27] was developed in Sweden. It assesses various aspects of the patient's self-esteem, and is scored by the children themselves. It was chosen for this study due to existing Swedish norms (z-scores; with a mean of 5, and SD of 2). Depending on the children's age two different scales were used, the L-scale ("Low stage") with 32 questions (scored -1 or +1 ) for children aged 7-10 years, summarized to a total L-score, and the MH-scale ("Middle-high stage") with 72 questions (scored -2 to +2 ) in the domains "Physical abilities", "Performance", "Psychic WellBeing", "Family Relations", and "Relations to Peers", and a total MH-score for children aged 11-16 years. For both scales, a high score indicates a high perceived competence.

The Children's Depression Rating Scale-Revised (CDRS-R) [31], a 17-item scale to measure presence and severity of depression scored by the clinician, is modeled after the Hamilton Depression Rating Scale for adults, but additionally includes questions about school. The total score ranges from 17 to 113 , with high scores indicating a high degree of depression.

QoL assessments were performed at baseline (Visit 2 for all QoL measures except for CDRS-R and FTF, for which baseline assessments were performed at Visit 1) and at the study endpoint (Visit 7, week 10).

Sample size determination

Although the CHIP-CE had been used in completed trials in somatically ill children, no data were published on its use in psychiatric samples at the time of initiation of the present study. The CHIP-CE is standardized on an US sample to $t$ 
scores, i.e., to mean $\pm \mathrm{SD}$ of $50 \pm 10$. A change of approximately $0.5 \mathrm{SD}$, i.e., $\sim 5$ points, is considered as a clinically relevant change (Riley A, personal communication). Approximately 100 patients were planned to be randomized to atomoxetine or placebo treatment in a 1:1 ratio. The sample size was calculated for $80 \%$ or more power to detect a difference of $\geq 6.0$ units on the standardized CHIP$\mathrm{CE}$ achievement domain mean score between treatment groups with respect to the change in score from baseline to that after 10 weeks of treatment. A 5\% significance level was used, and calculations were done with the Students $t$ test. The discontinuation rate was estimated to be $10 \%$.

\section{Statistics}

The primary efficacy analysis was the mean score of the CHIP-CE "Achievement" domain. The last observation carried forward (LOCF) change from baseline to endpoint was analyzed by an analysis of covariance (ANCOVA) model including terms for baseline score, treatment, site, visit, and treatment-by-visit interaction. Baseline was defined as scores obtained at Visit 2, before randomization. Furthermore, the analysis included the baseline CDRS-R score as a covariate in order to adjust for potential imbalances in this scale at baseline that may affect HRQL. Similar analyses were performed on the 4 other domains of the CHIP-CE ("Satisfaction", "Comfort", "Resilience", and "Risk avoidance"), the total scores of the CHIP-CE and the subdomains. The other HRQL questionnaires were analyzed using an ANCOVA model applied on the LOCF change from baseline to endpoint including terms for site, treatment, and baseline score. All analyses were conducted using PROC MIXED of the SAS ${ }^{\circledR}$ software. Estimates for the change within treatment group (incl. standard error) and for the difference between treatment groups plus corresponding $95 \%$ confidence interval (CI) and $P$ value, as well as descriptive statistics ( $N$, mean, standard deviation, median and range) were presented.

All statistical tests were 2-sided with a nominal significance level of 5\%. Analysis of the CHIP-CE-Parent form domains included adjustments of the significance levels for multiplicity.

\section{Results}

HRQL: efficacy results

At baseline, there were no relevant differences for the CHIP-CE total score or any of its domains between the two treatment groups (Table 1). At study endpoint, the mean change from baseline for the "Achievement" domain score was more than twice as high in the atomoxetine group (6.9) than in the placebo group (3.0), and this difference was statistically significant $(P=0.010)$. Similarly, the change in the "Risk avoidance" domain was statistically significantly higher $(P=0.041)$ in the atomoxetine group $(7.1)$ than in the placebo group (3.9). For all other changes in domains and the total CHIP-CE score differences between the two treatment groups were not statistically significant.

The impact of comorbid conditions, particularly ODD, on the change in CHIP-CE domain scores is of obvious interest for physicians treating patients with ADHD. Due to the relatively small sample size $(N=99)$, and the fact that only $20.2 \%$ of the patients $(n=19)$ fulfilled criteria for ODD, the statistical power to show a possible interaction of such comorbidity is insufficient in this pre-planned secondary analysis. Yet, the numerical improvement in all five

Table 1 CHIP-CE domain scores and total score

\begin{tabular}{|c|c|c|c|c|c|c|}
\hline \multirow{3}{*}{$\begin{array}{l}\text { CHIP-CE domain } \\
\text { Subdomain }\end{array}$} & \multirow{2}{*}{\multicolumn{2}{|c|}{ Baseline score [mean (SD)] }} & \multicolumn{4}{|c|}{ Endpoint score } \\
\hline & & & \multicolumn{2}{|c|}{ LS mean change from baseline (SE) } & \multicolumn{2}{|c|}{ Difference in LS means } \\
\hline & $\begin{array}{l}\text { Atomoxetine } \\
(N=49)\end{array}$ & $\begin{array}{l}\text { Placebo } \\
(N=50)\end{array}$ & $\begin{array}{l}\text { Atomoxetine } \\
(N=49)\end{array}$ & $\begin{array}{l}\text { Placebo } \\
(N=50)\end{array}$ & $\begin{array}{l}\text { Estimate } \\
(95 \% \text { CI })\end{array}$ & $P$ value \\
\hline Total score & $28.3(10.3)$ & $30.5(10.8)$ & $6.6(1.2)$ & $5.2(1.2)$ & $1.5(-1.8 ; 4.8)$ & 0.381 \\
\hline Achievement & $29.2(9.9)$ & $29.8(8.9)$ & $6.9(1.0)$ & $3.0(1.1)$ & $3.9(0.9 ; 6.8)$ & 0.010 \\
\hline Peer relations & $34.6(13.5)$ & $35.8(13.5)$ & $4.5(0.9)$ & $2.2(0.9)$ & $2.2(-0.3 ; 4.8)$ & 0.087 \\
\hline Academic performance & $32.0(10.0)$ & $31.3(8.0)$ & $6.7(1.2)$ & $2.4(1.3)$ & $4.2(0.8 ; 7.6)$ & 0.015 \\
\hline Satisfaction & $31.8(13.4)$ & $34.0(13.7)$ & $3.4(1.7)$ & $4.8(1.7)$ & $-1.4(-6.1 ; 3.2)$ & 0.540 \\
\hline Comfort & $44.1(9.1)$ & $44.1(8.7)$ & $3.3(1.1)$ & $4.7(1.2)$ & $-1.4(-4.5 ; 1.8)$ & 0.396 \\
\hline Resilience & $35.8(11.4)$ & $39.5(12.2)$ & $3.0(1.1)$ & $2.8(1.1)$ & $0.2(-3.0 ; 3.4)$ & 0.904 \\
\hline Risk avoidance & 32.7 (12.6) & 34.9 (11.9) & $7.1(1.1)$ & $3.9(1.1)$ & $3.2(0.1 ; 6.3)$ & 0.041 \\
\hline
\end{tabular}

Baseline and change from baseline to endpoint

CHIP-CE Child health and illness profile-child edition, $N$ maximum number of patients, $S D$ standard deviation, $L S$ least square, $S E$ standard error, $C I$ confidence interval 
domains was similar or greater for patients without ODD (range 0-2.1). For Achievement, patients on atomoxetine without/with ODD improved equally $[7.4(\mathrm{SD}=8.0)$ vs. 7.4 points $(\mathrm{SD}=11.5)$, respectively]. For Risk avoidance, corresponding values were 7.5 points $(S D=9.3)$ versus 6.7 points $(\mathrm{SD}=9.1)$, respectively.

The FSI total score as well as the scores for its domains "Emotional" and "Restriction" decreased from baseline to study endpoint with both treatments, with higher decreases in atomoxetine than in placebo patients (Table 2). The between group difference for the total FSI score was statistically significant (change of -2.2 in the atomoxetine group and -0.5 in the placebo group; $P=0.046$ ).

There were only minor changes from baseline to study endpoint in the section (I) domains of the ASCR (Table 3). The 2 treatment groups did not differ significantly with the only exception of the domain "Child as a burden", for which the mean change was -0.18 in the atomoxetine group and 0.05 in the placebo group $(P=0.007)$.
For all FTF domain sores, there was a larger decrease (i.e., improvement) in the atomoxetine group compared to the placebo group (Table 4). Between-treatment differences were statistically significant for all domains ( $P$ values between $<0.001$ and 0.033 ) with the exception of the "Language and Speech" domain $(P=0.115)$.

There were no statistically significant differences between atomoxetine and placebo in the "I think I am" total scores or the domains of the "I think I am" MH-scale (Table 5). Results showed no consistent trend for either treatment group as both increases (i.e., improvements) and decreases occurred depending on the score and/or the treatment group.

The CDRS-R total score decreased from baseline to study endpoint in the atomoxetine group (mean change of -3.4), whereas it remained almost unchanged in the placebo group (mean change of -0.1). The corresponding estimate for the difference between the two treatment groups of -3.3 was statistically significant $(P=0.033 ; 95 \%$ CI: $[-6.4 ;-0.3])$. Since only two patients in the atomoxetine group and three

Table 2 FSI total score and domain scores

\begin{tabular}{|c|c|c|c|c|c|c|}
\hline \multirow[t]{3}{*}{ FSI domain } & \multirow{2}{*}{\multicolumn{2}{|c|}{ Baseline score [mean (SD)] }} & \multicolumn{4}{|l|}{ Endpoint score } \\
\hline & & & \multicolumn{2}{|c|}{ LS mean change from baseline (SE) } & \multicolumn{2}{|c|}{ Difference in LS means } \\
\hline & $\begin{array}{l}\text { Atomoxetine } \\
(N=49)\end{array}$ & $\begin{array}{l}\text { Placebo } \\
(N=50)\end{array}$ & $\begin{array}{l}\text { Atomoxetine } \\
(N=49)\end{array}$ & $\begin{array}{l}\text { Placebo } \\
(N=50)\end{array}$ & $\begin{array}{l}\text { Estimate } \\
(95 \% \mathrm{CI})\end{array}$ & $P$ value \\
\hline Total score & $9.8(4.7)$ & $8.8(4.6)$ & $-2.2(0.6)$ & $-0.5(0.6)$ & $-1.8(-3.5 ; 0.0)$ & 0.046 \\
\hline Emotional & $3.4(1.7)$ & $3.3(1.7)$ & $-0.8(0.2)$ & $-0.3(0.2)$ & $-0.5(-1.1 ; 0.1)$ & 0.102 \\
\hline Restriction & $6.5(3.2)$ & $5.5(3.3)$ & $-1.4(0.5)$ & $-0.1(0.5)$ & $-1.2(-2.5 ; 0.0)$ & 0.056 \\
\hline
\end{tabular}

Baseline and change from baseline to endpoint

FSI family strain index, $N$ maximum number of patients, $S D$ standard deviation, $L S$ least square, $S E$ standard error, $C I$ confidence interval

Table 3 ASCR section (I) and section B scores

\begin{tabular}{|c|c|c|c|c|c|c|}
\hline \multirow[t]{3}{*}{ ASCR score } & \multirow{2}{*}{\multicolumn{2}{|c|}{ Baseline score [mean (SD)] }} & \multicolumn{4}{|c|}{ Endpoint score } \\
\hline & & & \multicolumn{2}{|c|}{ LS mean change from baseline (SE) } & \multicolumn{2}{|l|}{ Difference in LS means } \\
\hline & $\begin{array}{l}\text { Atomoxetine } \\
(N=49)\end{array}$ & $\begin{array}{l}\text { Placebo } \\
(N=50)\end{array}$ & $\begin{array}{l}\text { Atomoxetine } \\
(N=49)\end{array}$ & $\begin{array}{l}\text { Placebo } \\
(N=50)\end{array}$ & $\begin{array}{l}\text { Estimate } \\
(95 \% \text { CI })\end{array}$ & $P$ value \\
\hline \multicolumn{7}{|l|}{ Section (I) } \\
\hline Acceptance & $2.91(0.36)$ & $2.82(0.50)$ & $0.01(0.05)$ & $0.02(0.05)$ & $-0.01(-0.15 ; 0.13)$ & 0.888 \\
\hline Coping & $2.76(0.28)$ & $2.83(0.31)$ & $0.07(0.04)$ & $-0.04(0.04)$ & $0.10(-0.01 ; 0.22)$ & 0.069 \\
\hline Experiencing problems & $3.20(0.43)$ & $3.11(0.37)$ & $0.01(0.05)$ & $0.03(0.05)$ & $-0.01(-0.15 ; 0.13)$ & 0.871 \\
\hline Need for a change & $3.35(0.59)$ & $3.37(0.45)$ & $0.12(0.06)$ & $0.07(0.06)$ & $-0.05(-0.11 ; 0.21)$ & 0.549 \\
\hline Child as a burden & $3.29(0.39)$ & $3.15(0.44)$ & $-0.18(0.06)$ & $0.05(0.06)$ & $-0.24(-0.41 ;-0.06)$ & 0.007 \\
\hline Managing on ones own & $2.92(0.42)$ & $2.88(0.38)$ & $0.09(0.05)$ & $0.08(0.05)$ & $0.02(-0.12 ; 0.16)$ & 0.797 \\
\hline Pleasure & $1.76(0.58)$ & $1.69(0.57)$ & $-0.19(0.07)$ & $-0.13(0.07)$ & $-0.06(-0.25 ; 0.12)$ & 0.496 \\
\hline Relation & $3.26(0.55)$ & $3.33(0.63)$ & $0.12(0.07)$ & $0.13(0.07)$ & $-0.01(-0.21 ; 0.18)$ & 0.889 \\
\hline Section B & $4.53(1.43)$ & $4.52(1.38)$ & $-0.57(0.15)$ & $-0.36(0.15)$ & $-0.21(-0.63 ; 0.21)$ & 0.325 \\
\hline
\end{tabular}

Baseline and change from baseline to endpoint

$A S C R$ appraisal of stress in child-rearing, $N$ maximum number of patients, $S D$ standard deviation, $L S$ least square, $S E$ standard error, $C I$ confidence interval 
Table 4 FTF domain scores

\begin{tabular}{|c|c|c|c|c|c|c|}
\hline \multirow[t]{3}{*}{ FTF domain } & \multirow{2}{*}{\multicolumn{2}{|c|}{ Baseline score [mean (SD)] }} & \multicolumn{4}{|l|}{ Endpoint score } \\
\hline & & & \multicolumn{2}{|c|}{ LS mean change from baseline (SE) } & \multicolumn{2}{|l|}{ Difference in LS means } \\
\hline & $\begin{array}{l}\text { Atomoxetine } \\
(N=49)\end{array}$ & $\begin{array}{l}\text { Placebo } \\
(N=50)\end{array}$ & $\begin{array}{l}\text { Atomoxetine } \\
(N=49)\end{array}$ & $\begin{array}{l}\text { Placebo } \\
(N=50)\end{array}$ & $\begin{array}{l}\text { Estimate } \\
(95 \% \text { CI })\end{array}$ & $P$ value \\
\hline Motor control & $0.58(0.39)$ & $0.63(0.45)$ & $-0.18(0.03$ & $-0.06(0.03)$ & $-0.12(-0.21 ;-0.03)$ & 0.012 \\
\hline Executive function & $1.42(0.33)$ & $1.38(0.36)$ & $-0.39(0.05)$ & $-0.08(0.05)$ & $-0.31(-0.46 ;-0.17)$ & $<0.001$ \\
\hline Perception & $0.70(0.38)$ & $0.54(0.37)$ & $-0.20(0.04)$ & $-0.03(0.04)$ & $-0.17(-0.29 ; 0.06)$ & 0.004 \\
\hline Memory & $0.85(0.47)$ & $0.70(0.35)$ & $-0.11(0.04)$ & $0.02(0.04)$ & $-0.13(-0.26 ;-0.01)$ & 0.033 \\
\hline Language and speech & $0.60(0.43)$ & $0.43(0.30)$ & $-0.12(0.03)$ & $-0.06(0.03)$ & $-0.07(-0.15 ; 0.02)$ & 0.115 \\
\hline Learning & $1.15(0.44)$ & $1.13(0.37)$ & $-0.22(0.04)$ & $-0.07(0.04)$ & $-0.15(-0.27 ;-0.04)$ & 0.008 \\
\hline Social competence & $0.76(0.43)$ & $0.61(0.44)$ & $-0.20(0.04)$ & $-0.06(0.04)$ & $-0.14(-0.25 ;-0.04)$ & 0.009 \\
\hline Emotional/behavioral & $0.60(0.35)$ & $0.55(0.35)$ & $-0.18(0.03)$ & $-0.08(0.03)$ & $-0.10(-0.19 ;-0.01)$ & 0.031 \\
\hline
\end{tabular}

Baseline and change from baseline to endpoint

$N$ maximum number of patients, $S D$ standard deviation, $L S$ least square, $S E$ standard error, $C I$ confidence interval

Table 5 "I think I am" scores

\begin{tabular}{|c|c|c|c|c|c|c|}
\hline \multirow[t]{3}{*}{ "I think I am" score } & \multirow{2}{*}{\multicolumn{2}{|c|}{$\frac{\text { Baseline score }(n)}{\text { Mean }(\mathrm{SD})}$}} & \multicolumn{4}{|l|}{ Endpoint score } \\
\hline & & & \multicolumn{2}{|c|}{ LS mean change from baseline (SE) } & \multicolumn{2}{|c|}{ Difference in LS means } \\
\hline & $\begin{array}{l}\text { Atomoxetine } \\
(N=49)\end{array}$ & $\begin{array}{l}\text { Placebo } \\
(N=50)\end{array}$ & $\begin{array}{l}\text { Atomoxetine } \\
(N=49)\end{array}$ & $\begin{array}{l}\text { Placebo } \\
(N=50)\end{array}$ & $\begin{array}{l}\text { Estimate } \\
(95 \% \text { CI })\end{array}$ & $P$ value \\
\hline Total score & $\begin{array}{l}39 \\
4.97(1.63)\end{array}$ & $\begin{array}{l}34 \\
4.85(1.74)\end{array}$ & $0.28(0.25)$ & $0.13(0.26)$ & $0.15(-0.55 ; 0.85)$ & 0.671 \\
\hline L-scale total & $\begin{array}{l}12 \\
5.33(1.87)\end{array}$ & $\begin{array}{l}13 \\
5.31(1.97)\end{array}$ & $0.63(0.58)$ & $0.01(0.57)$ & $0.62(-1.05 ; 2.29)$ & 0.438 \\
\hline MH-scale total & $\begin{array}{l}27 \\
4.81(1.52)\end{array}$ & $\begin{array}{l}21 \\
4.57(1.57)\end{array}$ & $0.10(0.23)$ & $0.31(0.27)$ & $-0.21(-0.92 ; 0.50)$ & 0.553 \\
\hline MH-scale domains & & & & & & \\
\hline Physical abilities & $\begin{array}{l}31 \\
5.42(1.84)\end{array}$ & $\begin{array}{l}27 \\
5.67(2.02)\end{array}$ & $-0.51(0.27)$ & $-0.52(0.28)$ & $0.02(-0.75 ; 0.79)$ & 0.960 \\
\hline Performance & $\begin{array}{l}29 \\
4.66(1.97)\end{array}$ & $\begin{array}{l}26 \\
5.46(1.65)\end{array}$ & $0.32(0.24)$ & $-0.22(0.27)$ & $0.53(-0.19 ; 1.26)$ & 0.147 \\
\hline Physical well-being & $\begin{array}{l}31 \\
3.77(1.54)\end{array}$ & $\begin{array}{l}29 \\
3.59(1.74)\end{array}$ & $0.76(0.24)$ & $0.24(0.25)$ & $0.52)(-0.17 ; 1.20$ & 0.137 \\
\hline Family relations & $\begin{array}{l}30 \\
4.53(1.94)\end{array}$ & $\begin{array}{l}29 \\
4.52(1.90)\end{array}$ & $-0.29(0.31)$ & $0.08(0.32)$ & $-0.37(-1.25 ; 0.51)$ & 0.398 \\
\hline Relation to peers & $\begin{array}{l}28 \\
5.54(1.91)\end{array}$ & $\begin{array}{l}26 \\
4.77(1.95)\end{array}$ & $-0.14(0.30)$ & $0.10(0.32)$ & $-0.24(-1.12 ; 0.64)$ & 0.590 \\
\hline
\end{tabular}

Baseline and change from baseline to endpoint

$L$-scale children 7-10 years, $M H$-scale children 11-16 years, $n$ number of evaluable patients, $N$ maximum number of patients, $S D$ standard deviation, $L S$ least square, $S E$ standard error, $C I$ confidence interval

patients in the placebo group fulfilled criteria for major depressive disorder [39] (and the mean CDRS-R scores at baseline were as low as $\sim 25$; possible range 17-113), we do not consider this statistically significant difference to reflect proof of an antidepressant effect of atomoxetine, but rather an effect of overlapping items in the CDRS-R and ADHDRS scales, e.g., "work and activities".

\section{Discussion}

The baseline scores of mainly the CHIP-CE domains Achievement and Risk avoidance in the present study of Swedish treatment-naive children and adolescents with ADHD confirm the picture seen in previous European studies [32, 33]: the HRQL of these children is particularly 
negatively affected within the areas of school performance, peer relations, and risk taking behavior. Also CHIP-CE Satisfaction and Resilience were impaired compared to normal children. In this study, many of the patients' broader areas of functioning, i.e., HRQL and functional outcomes, improved significantly better under treatment with atomoxetine and psychoeducation than under placebo and psychoeducation. The mean change from baseline to study endpoint in the primary efficacy variable, the CHIPCE "Achievement" domain, was 6.9 in the atomoxetine group and 3.0 in the placebo group, which led to a statistically significant difference between treatment groups $(P=0.010)$. Additionally, the improvement in the "Risk avoidance" domain of the CHIP-CE was also statistically significantly larger for atomoxetine patients than for placebo patients. Thus, there were clear indications that patients treated with atomoxetine performed better in school compared to placebo-treated patients $(P=0.015)$, their peer relationships improved (although not statistically significant compared with placebo; $P=0.087$ ), and their risk taking behavior decreased. The FSI decreased significantly more for atomoxetine-treated patients than for placebo, indicating less worry and interruptions of activities in families of atomoxetine-treated patients. This finding is consistent with the results measured by the ASCR, which indicated a significant reduction of the perception of the "child as a burden", and a trend towards improvement in "family coping" in parents of atomoxetine-treated patients, and with the statistically significant changes in favor of atomoxetine treatment over placebo in seven of eight FTF developmental/neuropsychiatric domains (Motor control, Executive function, Perception, Memory, Learning, Social competence, and Emotional behavior).

No statistically significant differences were seen in the other CHIP-CE domains, Satisfaction, Resilience, and Comfort, which all include subdomains related to bodily functioning, i.e., areas usually not primarily affected in patients with ADHD. Furthermore, the baseline score of the domain Comfort was within the normal range ( $t$ score $\sim 44$ ), leaving very little space for change/differentiation between treatment groups. In the UK "Sunbeam" study [32], all five CHIP-CE domains and its total score managed to differentiate between atomoxetine treatment and standard current therapy. This may be explained by several differences between the two studies. In the UK study, all patients were eligible for pharmacological treatment. As a group, they were also more severely affected, with a severity of illness as measured with ADHD-RS scores at baseline of $\sim 45$, compared to 39 in the present study. In the present study, all patients were stimulant naive, and patients requiring immediate therapy were excluded. These baseline conditions of the UK study were also reflected in lower baseline values for some of the CHIP-CE domains, e.g., in $t$ scores for Satisfaction and Risk avoidance as low as $\sim 33-35$, and $\sim 20$, respectively. Finally, the fact that Sunbeam was an open-label study might have introduced a bias, which may have influenced the results.

Interestingly, the present results regarding the changes in CHIP-CE domains are consistent with the results of another placebo-controlled study, investigating HRQL in Spanish children and adolescents with ADHD (14). Similar to the present study, all patients were stimulant-naive, had a similar baseline severity (ADHD-RS 39), and comorbidity (prevalence of ODD 25.5\%). However, the statistical power was higher (151 patients), but no psychoeducation was given. In this Spanish study, only the CHIP-CE domains Achievement and Risk Avoidance, as assessed by parents improved significantly more in atomoxetine-treated patients compared to patients treated with placebo.

The significant changes in 7 out of 8 FTF domains indicate that atomoxetine does not only affect ADHD symptoms positively, but also many other areas of developmental/neuropsychiatric functioning. The domain score for Executive functioning was the most deviant at baseline. This is not surprising, since it consists of 27 variables, the main part of these being 2 subdomains covering 9 items each (attention, and hyperactivity/ impulsiveness), directly modeled on the DSM-IV criteria for ADHD. Two additional subdomains, Hypoactivity (4 variables) and Planning/organizing (3 variables), did also improve significantly better for atomoxetine than for placebo (post hoc analysis). The FTF domain Language and speech was the only one that did not differ significantly between the treatment arms, however, the mean baseline score for this domain was the lowest, i.e., the less deviant of the developmental areas of the entire study sample at baseline. Interestingly, the validity of the FTF baseline scores of the present study is supported by very similar FTF profiles presented in 2 Scandinavian studies in children and adolescents with a DSM-IV diagnosis of ADHD [1, 8].

The statistically significant advantage in CHIP-CE Achievement of $\sim 4$ points for atomoxetine and psychoeducation versus placebo and psychoeducation was somewhat smaller than the predefined difference of 5 points that the sample size calculation was based upon. We interpret this difference nevertheless as clinically relevant, in particular when also considering the results of the changes in other instruments of the present study. The very consistent changes in core HRQL measures in ADHD-patients, such as Achievement and Risk avoidance are in line with the improvements in the 7 FTF domains, the reduced parental experience of family strain (FSI), and child as a burden (ASCR).

These changes are also consistent with the pronounced decline in core ADHD symptoms in the atomoxetine group 
as compared to the placebo group. The possible influence of the psychoeducational intervention on the high effect size on the core ADHD symptoms of atomoxetine-treated patients in the present study (effect size of 1.3) is discussed in more detail by Svanborg and coworkers [39]. Since the effect of atomoxetine and psychoeducation was unusually high in the present study compared to other atomoxetine studies without psychoeducation, concurrent with a similar treatment response with placebo and psychoeducation as in placebo arms of these studies, it was hypothesized that the high effect size, at least partially, might be the result of an interaction between atomoxetine and psychoeducation, possibly in part supported by increased treatment compliance. Similar factors may have contributed to the above described effect on HRQL and functional measures.

However, other parent-rated functional areas related to physical functioning failed to differ between treatment groups, as did several measures of parent and patient assessments of subjective well-being, self-esteem and the emotional climate in the family. For both the ASCR and the "I think I am", comparative data from other studies in patient populations with ADHD is not available to provide better understanding of this lack of differentiation. The "I think I am" scale was chosen instead of Harter's [16] more known and internationally more frequently used instrument (e.g., in the Sunbeam study) due to the existence of Swedish norms for the "I think I am" scale. One possible reason for the lack of differentiation in the scores of this patient-assessed scale is the insufficient statistical power due to the split of the data sets in 2 age groups and due to missing data. The validity of self-assessments of ADHD children and adolescents has also been questioned [13]. Also in the SUNBEAM study, where all 5 CHIP-CE domains differentiated between the atomoxetine and SCT groups, only one of the 6 domains of the Harter scale, "scholastic competence" succeeded to differentiate between the groups. In the study by Escobar and coworkers described above [14], additional to parental CHIP-CE ratings also the child or adolescent version of the CHIP [37] was assessed and compared with parents' ratings. Interestingly, all CHIP domains were rated within the normal range by the patients. Baseline scores when assessed by a child or adolescent were consequently higher than the parents' score. However, among the patient-assessed domains, Achievement had the lowest baseline value $(m=42.1-44,6)$ and improved significantly more for atomoxetine-treated patients compared to patients treated with placebo. In sum, this signifies a disagreement between patients and parents reports of HRQL, but also that children with ADHD may acknowledge problems with social and academic functioning, which is a result in line with the SUNBEAM findings. One other possibility is that the treatment period of 10 weeks was not long enough to also show improvements in areas of possibly more slowly changing mind-sets such as subjective well-being, selfesteem, and self-image of patients as well as of parents. Further insight into this research question may be gained when data from the open-label continuation phase of the present study are analyzed.

At least two uncommon features of the present study may limit the generalizability of the results: the concomitant psychoeducation and the inclusion of only stimulantnaive patients. Even if pharmacological treatment, according to common treatment guidelines such as the European Guidelines [3, 26] or the Strattera ${ }^{\circledR}$ SPC [40] should always be only one part of a comprehensive treatment program, which also should include reinforcing psychosocial interventions, it's unclear to which degree such interventions are implemented in "the real world". In the present study, only four sessions of psychoeducation were given. This is fewer compared to other, more comprehensive educational programs, and may represent a weakness of the study. Anyhow, we believe that the high effect size on ADHD core symptoms in the present study was positively impacted by the psychoeducation (e.g., increased compliance, and/or a positive interaction effect between pharmacological and psychosocial treatments) and by inclusion of fewer treatment resistant patients (with no or few clear expectations of medication effects [39]) compared to other studies. However, in spite of all patients being stimulant naive, baseline severity in the present study was similar to that of other placebo-controlled atomoxetine trails. Due to the lack of a control group of patients receiving atomoxetine but without parental education, the impact of the psychoeducation on parents' ratings of the HRQL-related measures, i.e., on behaviors and functions not always obviously associated with the neuropsychiatric disorder, remains unclear.

The study was not designed to detect possible differing treatment effects on HRQL for patients with or without comorbidities like ODD. Thus, there is insufficient power to detect such interactions. However, an analysis of these interactions is currently planned for the combination of several studies using similar HRQL scales. Furthermore, analyses of long-term effects on the HRQL measures of the present study are underway, and will also be published separately.

\section{Conclusions}

Atomoxetine combined with psychoeducation had a positive effect on various everyday coping abilities of the patients as well as their families during 10 weeks of treatment, whereas the patients' self-image and the parents' image of the climate in the family were not shown to be 
significantly improved compared to placebo combined with psychoeducation.

Acknowledgments This research was funded by Eli Lilly Sweden AB. The following are acknowledged: Ansgar Dressler and Birgit von Janowsky, Trilogy Writing and Consulting GmbH, Frankfurt, Germany, for their help with preparation of this manuscript. Asa Nylen, former Sr Clinical Research Associate (Sr CRA) and in charge of the study operations, currently Medical liaison CNS, Eli Lilly Sweden AB. Lynne Poole, previously Dept Neuroscience Statistics Europe, Eli Lilly and Co Ltd, Basingstoke, UK, for statistical expertise during the preparation of this study protocol. The following investigators participated in the study: Bernt Danielsson M.D. (Mölnlycke), Lennart Eriksson M.D. (Örebro), Peter Gottfarb M.D. (Huddinge), Christina Högström M.D. (Lund), Mats Johnson M.D. (Göteborg), Eva Norén M.D. (Uppsala), Tatjana Olofsson M.D. (Umeå), Aivar Päären M.D. (Örebro), Mats Reimer M.D. (Mölnlycke). Authors Per A. Gustafsson M.D., Ph.D., Bruno Hägglöf M.D., Ph.D., Björn Kadesjö M.D., Ph.D., and Gunilla Thernlund M.D., Ph.D., were also investigators.

Open Access This article is distributed under the terms of the Creative Commons Attribution Noncommercial License which permits any noncommercial use, distribution, and reproduction in any medium, provided the original author(s) and source are credited.

\section{References}

1. Airaksinen EM, Michelsson K, Jokela V (2004) The occurrence of inattention, hyperactivity, impulsivity and coexisting symptoms in a population study of 471 6-8 year old children based on the FTF (Five to fifteen) questionnaire. Eur Child Adolesc Psychiatry 13(Suppl 3):III/23-III/30. doi:10.1007/s00787-004-3004-0

2. American Psychiatric Association (2000) Diagnostic and statistical manual of mental disorders. DSM-IV-TR, Washington DC

3. Banaschewski T, Coghill D, Santosh P, Zuddas A, Asherson P, Buitelaar J, Danckaerts M, Döpfner M, Faraone SV, Rothenberger A, Sergeant J, Steinhausen H-C, Sonuga-Barke EJS, Taylor E (2006) Long-acting medication for the hyperkinetic disorders. A systematic review and European treatment guidelines. Eur Child Adolesc Psychiatry. doi:10.1007/s00787-006-0549-0

4. Barkley RA (2002) Psychosocial treatments for attention-deficit/ hyperactivity disorder in children. J Clin Psychiatry 63(Suppl 12):36-43

5. Bernet W, Dulcan MK, Greenhill LL, Pliszka SR (2004) AACAP-endorsed managing: attention-deficit/hyperactivity disorder. Guidelines (Pocketcard) version 2.0 American Academy of Child and Adolescent Psychiatry. International Guidelines Center. Available at http://www.myguidelinescenter.com

6. Biederman J, Spencer T, Wilens T (2004) Evidence-based pharmacotherapy for the attention-deficit hyperactivity disorder. Int J Neuropsychopharmcol 7:77-97

7. Brown RT, Perewien A, Faries DE, Kratochvil CJ, Vaughan BS (2006) Atomoxetine in the management of children with ADHD: effect on quality of life and school functioning. Clin Pediatr 45:819-827

8. Bruce B, Thernlund G, Nettelbladt U (2006) ADHD and language impairment. A study of the parent questionnaire FTF (Five to fifteen). Eur Child Adolesc Psychiatry 15:52-60

9. Clarke SA, Eiser C (2004) The measurement of health-related quality of life (QoL) in paediatric clinical trials: a systematic overview. Health Qual Life Outcomes 2:66
10. Cunningham CE (1997) Readiness for change: applications to the design and evaluation of interventions for children with ADHD. The ADHD Report 5:6-9

11. Cunningham CE, Bremner RB, Boyle M (1995) Large group community-based parenting programs for families of preschoolers at risk for disruptive behaviour disorders: utilization, cost effectiveness, and outcome. J Child Psychol Psychiatr 36:11411159

12. Cunningham CE, Bremner RB, Secord-Gilbert M (2000) COPE: The Community Parent Education Program: a school based family systems oriented workshop for parents of children with disruptive behavior disorders (Leader's manual). COPE Works, Hamilton

13. Dankaerts M, Heplinstall E, Chadwick O, Taylor E (1999) Self report of attention deficit and hyperactivity in adolescents. Psychopathology 32(2):81-92

14. Escobar R, Montoya A, Polavieja P, Cardo E, Artigas J, Hervas A, Fuentes J (2009) Evaluation of patients' and parents' quality of life evaluation in a randomized placebo-controlled atomoxetine study in ADHD. J Child Adolesc Psychopharm (in press)

15. Escobar R, Soutullo CA, Hervas A, Gastaminza X, Polavieja P, Gilaberte I (2005) Worse quality of life for children with newly diagnosed attention-deficit/hyperactivity disorder, compared with asthmatic and healthy children. Pediatrics 116:364-369

16. Harter S (1985) Manual for the self-perception profile for children. University of Denver Press, Denver

17. Kadesjö B, Janols L-O, Korkman M, Mickelsson K, Strand G, Trillingsgaard A, Gillberg C (2004) The FTF (Five to Fifteen): the development of a parent questionnaire for the assessment of ADHD and comorbid conditions. Eur Child Adolesc Psychiatry 13(Suppl 3):III/3-III/13. doi:10.1007/s00787-004-3002-2

18. Kadesjö C, Stenlund H, Wels P, Gillberg C, Hägglöf B (2002) Appraisals of stress in child-rearing in Swedish mothers preschoolers with ADHD. Eur Child Adolesc Psychiatry 11:185195. doi:10.1007/s00787-002-0281-3

19. Kaufman J, Birmaher B, Brent D, Rao U, Flynn C, Moreci P, Williamson D, Ryan N (1997) Schedule for affective disorders and schizophrenia for school-age children-present and lifetime version (K-SADS-PL): initial reliability and validity data. J Am Acad Child Adolesc Psychiatry 36(7):980-989

20. Landgraf JM, Abetz L, Ware JE (1999) The CHQ user's manual. HealthAct, Boston

21. Landgraf JM, Maunsell E, Nixon Speechley K, Bullinger M, Campbell S, Abetz L, Ware JE (1998) Canadian-French, German and UK versions of the child health questionnaire: methodology and preliminary item scaling results. Qual Life Res 7:433-445

22. Matza LS, Rentz AM, Secnik K, Swensen AR, Revicki DA, Michelson D, Spencer T, Newcorn JH, Kratochvil CJ (2004) The link between health-related quality of life and clinical symptoms among children with attention-deficit hyperactivity disorder. Dev Behav Pediatr 25(3):166-174

23. Michelson D, Allen AJ, Busner J, Casat C, Dunn D, Kratochvil C, Newcorn J, Sallee FR, Sangal RB, Saylor K, West S, Kelsey D, Wenicke J, Trapp NJ, Harder D (2002) Once-daily atomoxetine treatment for children and adolescents with attention deficit hyperactivity disorder: a randomized, placebo-controlled study. Am J Psychiatry 159:1896-1901

24. Michelson D, Faries DE, Wernicke J, Kelsey D, Kendrick K, Sallee FR, Spencer T, The Atomoxetine ADHD Study Group (2001) Atomoxetine in treatment of children and adolescents with attention deficit/hyperactivity disorder: a randomized, placebocontrolled, dose-response study. Pediatrics 108(5):e83 (1-9)

25. Myrén K-J, Thernlund G, Nylén Å, Schacht A, Svanborg P (2009) Atomoxetine's effects on societal costs in Sweden. J Attention Dis. doi:10.1177/1087054709332163 
26. NICE (2006) http://www.nice.org.uk/guidance/index.jsp?action= byID\&o=11572

27. Ouvinen-Birgerstam P (1985) I think I am: Jag tycker jag är: manual (Swedish). Psykologiförlaget Stockholm 1985

28. Patterson GR, Chamberlain P (1992) A functional analysis of resistance (A neobehavioral perspective). In: Akowitz $\mathrm{H}$ (ed) Why don't people change? New perspectives on resistance and noncompliance. Guilford Press, New York

29. Perwien AR, Faries DE, Kratochvil CJ, Sumner CR, Kelsey DK, Allen AJ (2004) Improvement in health-related quality of life in children with ADHD: an analysis of placebo controlled studies of atomoxetine. Dev Behav Pediatr 25(4):264-271

30. Perwien AR, Kratochvil CJ, Faries DE, Vaughan BS, Spencer T, Brown RT (2006) Atomoxetine treatment in children and adolescents with attention-deficit hyperactivity disorder: what are the long-term health-related quality of life outcomes? J Child Adolesc Psychopharmacol 16(6):713-724

31. Poznaski E, Mokros HB (1999) Children's depression rating scale, revised. (CDRS-R). Western Psychological Services, Los Angeles

32. Prasad S, Harpin V, Poole L, Zeitlin H, Jamdar S, Puvanendran K (2007) A multi-centre, randomized, open-label study of atomoxetine compared with standard current therapy in UK children and adolescents with attention deficit/hyperactivity disorder (ADHD). Curr Med Res Opin 23(2):379-394

33. Ralston SJ, Lorenzo M, ADORE Study Group (2004) ADOREattention-deficit hyperactivity disorder observational research in Europe. Eur Child and Adolesc Psychiatry (Suppl 1) I/36-I/42

34. Remschmidt H, Global ADHD Working Group (2005) Global consensus on ADHD/HKD. Eur Child Adolesc Psychiatry 14(3):127-137
35. Riley AW, Chan KS, Prasad S, Poole L (2007) A global measure of child health-related quality of life: reliability and validity of the child health and illness profile-child editon (CHIP-CE) global score. J Med Econ 10:91-106

36. Riley AW, Coghill D, Forrest CB, Lorenzo MJ, Ralston SJ, Spiel G (2006) Validity of the health-related quality of life assessment in the ADORE study: parent report form of the CHIP-CE edition. Eur Child Adolesc Psychiatry 15(Suppl 1):I/63-I/71

37. Riley AW, Forrest CB, Starfield B, Rebok GW, Robertson JA, Green BF (2004) The parent report form of the CHIP-Child edition: reliability and validity. Med Care 42(3):210-220

38. Riley AW, Lyman LM, Spiel G, Döpfner M, Lorenzo MJ, Ralston SJ (2006) The family strain index (FSI). Reliability, validity, and factor structure of a brief questionnaire for families of children with ADHD. Eur Child Adolesc Psychiatry 15(Suppl 1):I/ $72-\mathrm{I} / 78$

39. Svanborg P, Thernlund G, Gustafssson PA, Hägglöf B, Poole L, Kadesjö B (2009) Efficacy and safety of atomoxetine as add-on to psychoeducation in the treatment of attention deficit/hyperactivity disorder-a randomized, double-blind, placebo-controlled study in Swedish children and adolescents. Eur Child Adolesc Psychiatry 18:240-249. doi:10.1007/s00787-008-0725-5

40. UK Strattera SPC (2007)

41. Weiss M, Tannock R, Kratochvil C, Dunn D, Velez-Borras J, Thomason C, Tamura R, Kelsey D, Stevens L, Allen AJ (2005) A randomized, placebo-controlled study of once-daily atomoxetine in the school setting in children with ADHD. J Am Acad Child Adolesc Psychiatry 44:647-655 